\title{
In response to oxidative stress, the expression of inflammatory cytokines and antioxidant enzymes are impaired in placenta, but not adipose tissue, of women with gestational diabetes
}

\author{
Martha Lappas ${ }^{1,2,3}$, Amberlee Mittion ${ }^{1,2}$ and Michael Permezel ${ }^{1,2}$ \\ ${ }^{1}$ Department of Obstetrics and Gynaecology and ${ }^{2}$ Mercy Perinatal Research Centre, Mercy Hospital for Women, University of Melbourne, Level 4/163 Studley \\ Road, Heidelberg 3084, Victoria, Australia \\ ${ }^{3}$ Translational Proteomics, Baker IDI, Melbourne 3004, Victoria, Australia \\ (Correspondence should be addressed to M Lappas; Email: mlappas@unimelb.edu.au)
}

\begin{abstract}
In response to oxidative stress, gestational diabetes mellitus (GDM) placenta releases less 8-isoprostane and tumour necrosis factor (TNF) $\alpha$. The effect of oxidative stress on other cytokines and antioxidant gene expressions are unknown. The aim of this study is to further explore the antioxidant status and effect of oxidative stress in GDM tissue. Human placenta, omental and subcutaneous adipose tissue from women with and without GDM were exposed to hypoxanthine $(\mathrm{HX}) / x a n t h i n e$ oxidase $(\mathrm{XO})$. Cytokine release was analysed by ELISA and cytokine and antioxidant gene expression by RT-PCR. Catalase $(C A T)$ and glutathione reductase $(G S R)$ mRNA expression was higher in GDM $(n=18)$ compared with normal $(n=23)$ placenta. There was no difference in glutathione peroxidase and superoxide dismutase mRNA expression. Antioxidant gene expression was unaltered between normal $(n=18)$ and GDM $(n=10)$ adipose tissue. HX/XO treatment significantly
\end{abstract}

stimulated cytokine release (13/16 cytokines) and cytokine mRNA expression, and decreased antioxidant gene expression (CAT and GSR) in human placenta from normal pregnant women. In GDM placenta, $\mathrm{HX} / \mathrm{XO}$ only significantly increased the release of $3 / 16$ cytokines, while there was no effect on antioxidant gene expression. In normal and GDM adipose tissues, $\mathrm{HX} / \mathrm{XO}$ increased proinflammatory cytokine and 8-isoprostane release, while there was no change in antioxidant gene expression. GDM placenta is characterised by increased antioxidant gene expression, and is less responsive to exogenous oxidative stress than tissues obtained from normal pregnant women. This may represent a protective or adaptive mechanism to prevent damage from further oxidative insult in utero as indicated by increased tissue antioxidant expression.

Journal of Endocrinology (2010) 204, 75-84

\section{Introduction}

Gestational diabetes mellitus (GDM) is a glucose intolerance of varying severity with onset or first recognition during pregnancy that complicates $\sim 2-4 \%$ of pregnancies (Beischer et al. 1996). Both patients with GDM, and their offspring, have greater risk of developing type 2 diabetes later in life (Lee et al. 2007). GDM is considered a pre-diabetic state or a transient unmasking of the metabolic syndrome, offering a unique opportunity to study abnormalities that may appear very early in the development of type 2 diabetes (KautzkyWiller et al. 1997). Increased biomarkers of oxygen radical damage and an impairment of antioxidant defence have been identified in individuals with type 2 diabetes (Baynes 1991, West 2000) and in women with GDM (Kinalski et al. 2001, Coughlan et al. 2004a, Lappas et al. 2004, Biri et al. 2006). We have previously demonstrated that, in GDM placenta, antioxidant activity is increased (Coughlan et al. 2004a), and have a reduced capacity to respond to oxidative stress in terms of 8-isoprostane (marker of lipid peroxidation) and tumour necrosis factor $\alpha$ (TNF $\alpha$ ) release (Coughlan et al. 2004b). We concluded that GDM placenta may be pre-conditioned by transient intracellular oxidative stress, which attenuates its responsiveness to further oxidative insult. However, the effect of oxidative stress on antioxidant gene expression and other inflammatory cytokines is not known. Furthermore, the antioxidant status and effect of oxidative challenge on other GDM tissues is also yet to be elucidated.

Oxidative stress refers to a disturbance in the balance between the production of reactive oxygen species (ROS) and antioxidant defences (West 2000). Abnormally high levels of free radicals and the simultaneous decline of antioxidant defence mechanisms can damage cellular lipids, proteins or DNA inhibiting their normal function. Because of this, oxidative stress has been implicated in a number of human diseases. In GDM placenta, there is an increase in oxidative 
stress and lipid peroxidation compared with normal pregnant women (Trocino et al. 1995, Coughlan et al. 2004a, Lappas et al. 2004), but there also appears to be a concomitant increase in antioxidant enzyme activity that compensates for the increased oxidative stress (Kinalski et al. 2001, Chaudhari et al. 2003, Coughlan et al. 2004a, Peuchant et al. 2004, Madazl et al. 2008). It is, however, not known if this increased antioxidant capacity is due to a reduction in gene expression in GDM placenta or the result of the increased biological oxidation that leads to a loss of antioxidant protein function. As there is no data available on antioxidant enzyme gene expression of placenta and other GDM tissues, the aim of this study is to compare the mRNA expression of endogenous antioxidant proteins in placenta, and subcutaneous and omental adipose tissue from healthy pregnant women and women with GDM.

Oxidative stress due to excessive ROS and weakened antioxidant defences is causally associated with inflammation and inflammatory mediators (Singh et al. 2005). Our previous studies have shown that xanthine oxidase (XO), which is one of the sources of free radical formation in diabetes (Desco et al. 2002), increases 8-isoprostane and $\mathrm{TNF} \alpha$ release in normal placenta but not in GDM placenta (Coughlan et al. 2004b). To further elucidate the mechanisms that mediate GDM-induced differences in placental tissue in response to oxidative stress, we tested the effect of $\mathrm{XO}$ on antioxidant capacity and a panel of inflammatory cytokines in placenta obtained from normal pregnant women and women with GDM. Additionally, to elucidate if an oxidative challenge elicits similar effects in other GDM tissues, the effect of XO treatment on subcutaneous and omental adipose tissue antioxidant gene expression and cytokine release from women with and without GDM will also be investigated. It should be noted, that in our previous studies, the experiments were performed in the presence of very high oxygen concentrations $\left(95 \% \mathrm{O}_{2}\right)$, which we previously have shown to induce inflammation, oxidative stress and apoptosis (Reti et al. 2007). Therefore, in this study, placenta will be incubated in the $8 \% \mathrm{O}_{2}$ (as the in utero-foetal organs are exposed to relatively hypoxic tensions (Evans et al. 1986)), and adipose tissue in the presence of $21 \% \mathrm{O}_{2}$.

\section{Materials and Methods}

\section{Tissue collection and preparation}

Human placenta, subcutaneous adipose tissue (from the anterior abdominal wall) and omental adipose tissue were obtained from a total of 40 pregnant women (23 healthy pregnant women and 17 with GDM) at the time of term Caesarean section before the onset of labour (Table 1). Indications for Caesarean section included repeat Caesarean section or breech presentation. Women with any adverse underlying medical condition (i.e. including asthma, preeclampsia and pregestational diabetes) were excluded. All pregnant women were screened for GDM, and women participating in the normal group had a negative screen. Women with GDM were diagnosed according to the criteria of the Australasian Diabetes in Pregnancy Society by either a fasting venous plasma glucose level of $\geq 5.5 \mathrm{mmol} / 1$ glucose, and/or $\geq 8.0 \mathrm{mmol} / 1$ glucose $2 \mathrm{~h}$ after a $75 \mathrm{~g}$ oral glucose load at $\sim 28$ weeks of gestation. All women with GDM were prescribed insulin in addition to dietary management. Approval for this study was obtained from the Mercy Hospital for Women's Research and Ethics Committee and informed consent was obtained from all participating subjects.

Tissues were obtained within $10 \mathrm{~min}$ of delivery and dissected fragments were placed in ice-cold DMEM (containing $5 \mathrm{mM}$ glucose, $100 \mathrm{U} / \mathrm{ml}$ penicillin $\mathrm{G}$ and $100 \mu \mathrm{g} / \mathrm{ml}$ streptomycin). A placental lobule (cotyledon) was removed from the central region of the placenta, the basal plate and chorionic surface were removed from the cotyledon, and villous tissue was obtained from the middle cross section. Placental tissues were blunt dissected to remove visible connective tissue and calcium deposits. Adipose tissue was thoroughly washed in ice-cold PBS to remove blood, and then cut into $2 \mathrm{~mm}^{2}$ pieces. A piece of the tissue was snap frozen in liquid nitrogen and stored at $-80{ }^{\circ} \mathrm{C}$ until required for RNA extraction. The remaining tissue was placed in DMEM at $37{ }^{\circ} \mathrm{C}$ in a humidified atmosphere of $5 \% \mathrm{CO}_{2}, 8 \%$ $\mathrm{O}_{2}$ for placenta and $21 \% \mathrm{O}_{2}$ for adipose tissue for $1 \mathrm{~h}$. Explants were blotted dry on sterile filter paper and transferred to 24-well tissue culture plates (100 mg wet weight/well). The explants were incubated in $2 \mathrm{ml}$ DMEM. The procedure for each tissue performed in duplicate for each treatment. To induce oxidative stress, explants were exposed to $0.5 \mathrm{mM}$ hypoxanthine (HX) and $15 \mathrm{mU} / \mathrm{ml} \mathrm{XO}$ in a humidified atmosphere of $5 \% \mathrm{CO}_{2}$ and $8 \% \mathrm{O}_{2}$ for placenta, and $5 \% \mathrm{CO}_{2}$ and $21 \% \mathrm{O}_{2}$ for adipose tissue for $24 \mathrm{~h}$. The concentrations of $\mathrm{HX}$ and $\mathrm{XO}$ were based on the results obtained from our previously published studies (Coughlan et al. 2004a). After the $24 \mathrm{~h}$ incubation, tissue and medium was collected separately and stored at $-80^{\circ} \mathrm{C}$.

Table 1 Characteristics of the study group. Values represent mean \pm S.E.M.

\begin{tabular}{lcc} 
& $\begin{array}{c}\text { Control } \\
\text { patients } \\
(n=23)\end{array}$ & $\begin{array}{c}\text { GDM } \\
\text { patients } \\
(n=17)\end{array}$ \\
\cline { 2 - 2 } Maternal age (years) & $31 \cdot 8 \pm 0 \cdot 8$ & $32 \cdot 6 \pm 1 \cdot 0$ \\
Maternal BMI (kg/m $)^{\mathrm{a}}$ & $28 \cdot 9 \pm 1 \cdot 5$ & $30 \cdot 0 \pm 2 \cdot 0$ \\
Gestational age at birth (weeks) & $38 \cdot 8 \pm 0 \cdot 1$ & $38 \cdot 2 \pm 0 \cdot 2$ \\
Foetal birth weight $(\mathrm{g})$ & $3408 \pm 88$ & $3314 \pm 98$ \\
Fasting plasma glucose (mmol/l) & $4 \cdot 4 \pm 0 \cdot 1$ & $4 \cdot 9 \pm 0 \cdot 1^{*}$ \\
1 h plasma glucose $(\mathrm{mmol} / \mathrm{l})$ & $6 \cdot 7 \pm 0 \cdot 4$ & $10 \cdot 4 \pm 0 \cdot 3 *$ \\
2 h plasma glucose $(\mathrm{mmol} / \mathrm{l})$ & $5 \cdot 5 \pm 0 \cdot 2$ & $8 \cdot 8 \pm 0 \cdot 3 *$
\end{tabular}

NS, not significant. $* P<0 \cdot 05$ versus normal patients.

${ }^{\mathrm{a}}$ Based on first antenatal visit at $\sim 12$ weeks. 
A

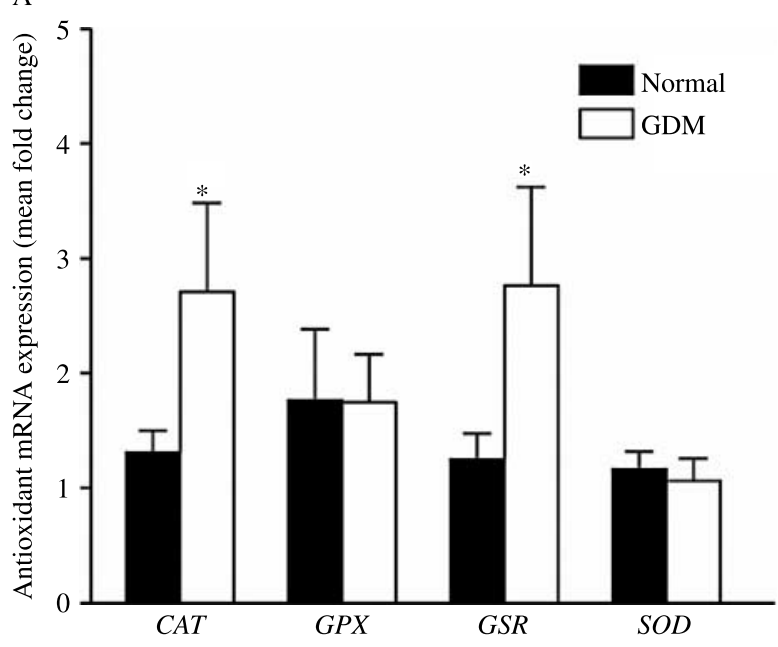

B

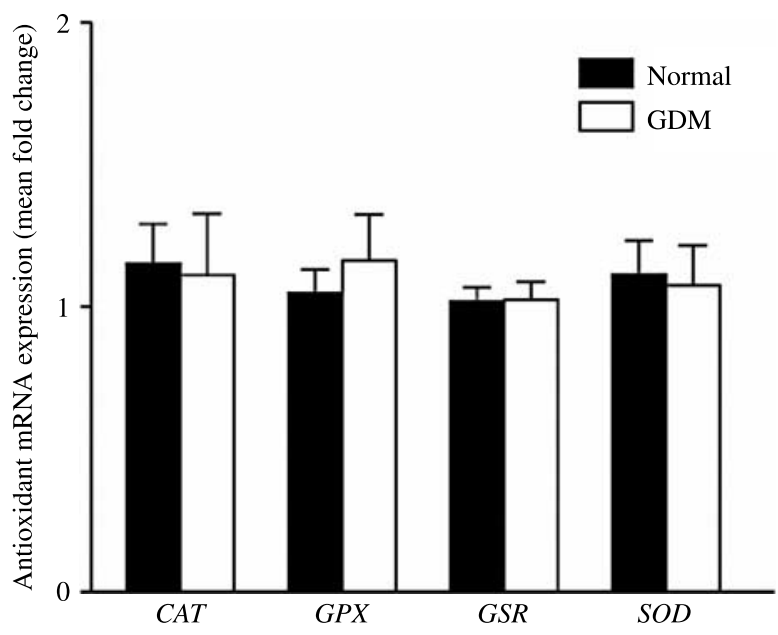

$\mathrm{C}$

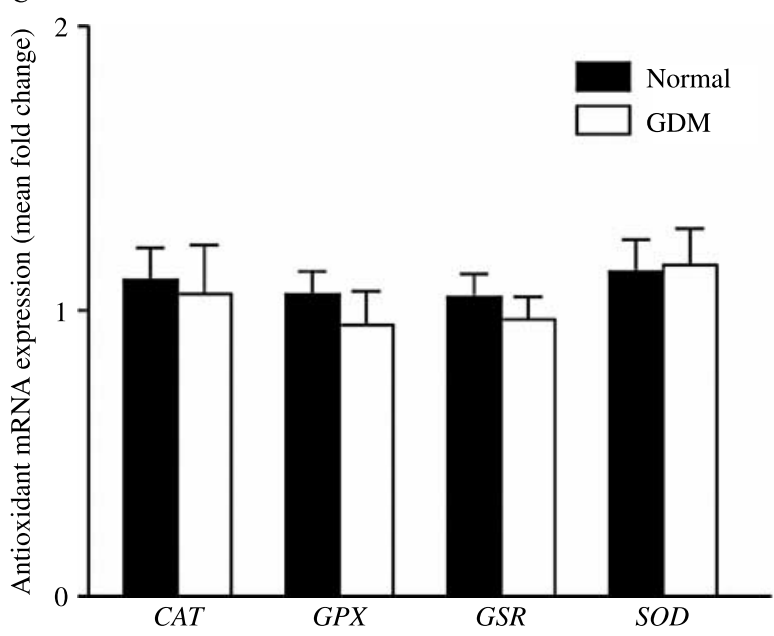

Validation of explant cultures and viability

To determine the effect of treatment on cell membrane integrity, the release of the intracellular enzyme lactate dehydrogenase (LDH) into incubation medium was determined as previously described (Lappas et al. 2004). $\mathrm{LDH}$ release was investigated over the $24 \mathrm{~h}$ time course of tissue explants. Explants were incubated in either medium alone or medium containing $0.5 \mathrm{mM} \mathrm{HX}$ and $15 \mathrm{mU}$ XO. Neither in vitro incubation nor experimental treatment significantly affected LDH activity in the incubation medium (data not shown). These data indicate that the concentrations used in this study did not affect cell viability.

Cytokine assays

For placenta After 24-h incubation, the explant incubation medium was collected and the release of cytokines was performed using the Bio-Plex suspension assay system and 17-plex human cytokine assay kit (Bio-Rad Laboratories). The system uses fluorescent-coded polystyrene beads, each of which is conjugated with a specific antibody and used to create a sandwich immunoassay. Sample and fluorochrome-conjugated antibody are allowed to react with the antibodyconjugated beads in micro plate wells. The assay utilised $50 \mu \mathrm{l}$ incubation medium. The panel included pro- and antiinflammatory cytokines as well as chemokines. The limit of detection varied for each cytokine and ranged from $0 \cdot 2$ to $3 \mathrm{pg} / \mathrm{ml}$. For all assays, the manufacturer's specifications indicated that the intra- and interassay coefficients of variation are $<10 \%$. Cytokine assays were read using the Bio-Plex workstation (Bio-Rad Laboratories) and results analysed with Bio-Plex Manager (v3.0) software. All data were corrected for total protein and expressed as $\mathrm{pg} / \mathrm{mg}$ protein. The protein content of tissue homogenates was determined using BCA protein assay (Pierce, Rockford, IL, USA), using BSA as a reference standard, as previously described (Lappas et al. 2004).

For adipose tissue After 24-h incubation, the explant incubation medium was collected and the release of TNF $\alpha$, IL6 and IL8 was performed by sandwich ELISA according to the manufacturer's instructions (Invitrogen). ELISA assays were read using a Benchmark microplate reader (Bio-Rad Laboratories) and results analysed with Microplate Manager (v4.0) software. All data were corrected for total protein and expressed as $\mathrm{pg} / \mathrm{mg}$ protein.

Figure 1 (A) Antioxidant gene expression in the placenta from healthy pregnant women $(n=23)$ at term and women with GDM $(n=17)$. (B) Antioxidant gene expression in the omental adipose tissue from healthy pregnant women $(n=18)$ at term and women with GDM $(n=10)$. (C) Antioxidant gene expression in the subcutaneous adipose tissue from healthy pregnant women $(n=18)$ at term and women with GDM $(n=10)$. 18S mRNA expression was used for the normalisation of the data. Gene expression is displayed as mean fold change ratio as calculated by the $2^{-\Delta \Delta C_{t}}$ method. All data is displayed as the mean \pm s.E.M. ${ }^{*} P<0 \cdot 05$ versus normal antioxidant mRNA expression. 
Table 2 Effect of hypoxanthine (HX)/xanthine oxidase (XO) on placental cytokine release

\begin{tabular}{|c|c|c|c|c|}
\hline & \multicolumn{2}{|l|}{ Normal $(n=7)$} & \multicolumn{2}{|l|}{$\operatorname{GDM}(n=7)$} \\
\hline & Basal & $\mathrm{HX} / \mathrm{XO}$ & Basal & $\mathrm{HX} / \mathrm{XO}$ \\
\hline \multicolumn{5}{|l|}{ Analyte (pg/ml) } \\
\hline IL2 & $17 \cdot 0 \pm 1 \cdot 9$ & $23 \cdot 9 \pm 2 \cdot 5^{*}$ & $12 \cdot \overline{8} \pm 3 \cdot 7$ & $13 \cdot 7 \pm 3 \cdot 3$ \\
\hline IL4 & $12 \cdot 5 \pm 2 \cdot 1$ & $19 \cdot 2 \pm 2 \cdot 1^{*}$ & $9 \cdot 5 \pm 3 \cdot 2$ & $10 \cdot 5 \pm 2 \cdot 0$ \\
\hline IL5 & ND & $\mathrm{ND}$ & $N D$ & ND \\
\hline IL $8^{\mathrm{a}}$ & $29 \cdot 6 \pm 8 \cdot 2$ & $58 \cdot 4 \pm 9 \cdot 5^{*}$ & $16 \cdot 4 \pm 5 \cdot 8$ & $13 \cdot 6 \pm 4 \cdot 3$ \\
\hline IL10 & $5 \cdot 8 \pm 1 \cdot 0$ & $20 \cdot 8 \pm 3 \cdot 0 *$ & $3 \cdot 9 \pm 1 \cdot 3$ & $4 \cdot 6 \pm 1 \cdot 2$ \\
\hline IL12(p70) & $17 \cdot 6 \pm 5 \cdot 1$ & $28 \cdot 8 \pm 2 \cdot 9 *$ & $11 \cdot 2 \pm 2 \cdot 3$ & $16 \cdot \overline{4} \pm 2 \cdot 9$ \\
\hline IL13 & $6 \cdot 6 \pm 1 \cdot 0$ & $5 \cdot 8 \pm 0 \cdot 7$ & $5 \cdot 7 \pm 1 \cdot 4$ & $7 \cdot 2 \pm 2 \cdot 1$ \\
\hline IL17 & $40 \cdot 8 \pm 7 \cdot 8$ & $86 \cdot \overline{4} \pm 9 \cdot 6^{*}$ & $27 \cdot \overline{3} \pm 9 \cdot 5$ & $21 \cdot 9 \pm 4 \cdot 9$ \\
\hline G-CSF & $955 \cdot 2 \pm 256 \cdot 2$ & $2144 \pm 616^{*}$ & $865 \cdot 0 \pm 619 \cdot 8$ & $285 \cdot 3 \pm 102 \cdot 6$ \\
\hline GM-CSF & $41 \cdot 5 \pm \overline{5} \cdot 5$ & $61 \cdot 3 \pm 7 \cdot 2 *$ & $29 \cdot 1 \pm 8 \cdot 7$ & $30 \cdot 9 \pm \overline{5} \cdot 7$ \\
\hline
\end{tabular}

${ }^{*} P<0 \cdot 05$ versus basal expression from normal placenta (paired Student's $t$-test). ${ }^{\dagger} P<0 \cdot 05$ versus basal cytokine release from GDM placenta (paired Student's t-test). ND, not detected.

${ }^{\mathrm{a}}$ Data in $\mathrm{ng} / \mathrm{ml}$.

\section{8-Isoprostane release}

The release of 8 -isoprostane, prostaglandin $(\mathrm{PG}) \mathrm{E}_{2}$ and $\mathrm{PGF}_{2 \alpha}$ into the incubation medium was assayed using a commercially available competitive enzyme immunoassay kit according to the manufacturer's specifications (Cayman Chemical Company, Ann Arbor, MI, USA). All data were corrected for total protein and expressed as $\mathrm{pg} / \mathrm{mg}$ protein.

\section{$R N A$ extraction and real time PCR}

Total RNA was extracted from $\sim 100 \mathrm{mg}$ of tissue using Tri Reagent according to manufacturer's instructions (SigmaAldrich). RNA concentrations were quantified using a spectrophotometer (Smart Spec, Bio-Rad). RNA quality and integrity were determined via the $A_{260} / A_{280}$ ratio and agarose gels electrophoresis. One microgram of RNA was converted into cDNA using the SuperScript VILO cDNA Synthesis Kit (Invitrogen) according to the manufacture's instructions. The cDNA was diluted tenfold, and $2 \mu \mathrm{l}$ cDNA was used to perform RT-PCR using Sensimix Plus SYBR green (Quantace, Alexandria, NSW, Australia) and $100 \mathrm{nM}$ the following primers: catalase (CAT) (Hs_CAT_1_SG QuantiTect Primer Assay, QT00079674); glutathione peroxidase (GPX) (Hs_GPX1_1_SG QuantiTect Primer Assay, QT00203392); glutathione reductase (GSR) (Hs_GSR_1_SG QuantiTect Primer Assay, QT00038325); superoxide dismutase (SOD) (Hs_SOD3_2_SG QuantiTect Primer Assay, QT01664327); TNF $\alpha$ (Hs_TNF_3_SG QuantiTect Primer Assay, QT01079561); IL6 (Hs_IL6_1_SG QuantiTect Primer Assay, QT00083720); IL8 (Hs_IL8_1_SG QuantiTect Primer Assay, QT00000322); and 18S (Hs_RRN18S_1_SG
QuantiTect Primer Assay, QT00199367). All primers were purchased from Qiagen. The specificity of the product was assessed from the melting curve analysis. RNA without reverse transcriptase during cDNA synthesis as well as PCRs using water instead of template showed no amplification. A positive control sample was also used in each run, on each plate.

Following baseline correction, the fluorescence threshold level was set during the geometric (exponential) phase of PCR amplification to generate the threshold cycle $\left(C_{\mathrm{t}}\right)$ value for each amplification curve. Average gene $C_{t}$ values were normalised to the average 18S RNA $C_{t}$ values of the same cDNA sample. Variations in gene expression were calculated by the comparative $C_{t}$ method that compares test samples to a calibrator sample. This method uses results obtained for a uniformly expressed control gene to correct for differences in the amount of RNA present in the two samples being compared in order to generate a $\Delta C_{\mathrm{t}}$ value. Fold differences were determined using the $2^{-\Delta \Delta C_{\mathrm{t}}}$ method (Livak \& Schmittgen 2001).

\section{Statistical analysis}

Statistical analyses were performed using a commercially available statistical software package (Statgraphics Plus version 3.1, Statistical Graphics Corp., Rockville, MD, USA). For expression data, Student's $t$-test was used to assess statistical significance between normally distributed data; otherwise, the non-parametric Mann-Whitney $U$ (Wilcoxon) test was used. Paired Student's $t$-test was used to compare the effect of $\mathrm{HX} / \mathrm{XO}$ on cytokine and antioxidant expression. Statistical difference was indicated by a $P$ value of $<0 \cdot 05$. Data are expressed as mean \pm S.E.M. 


\section{Results}
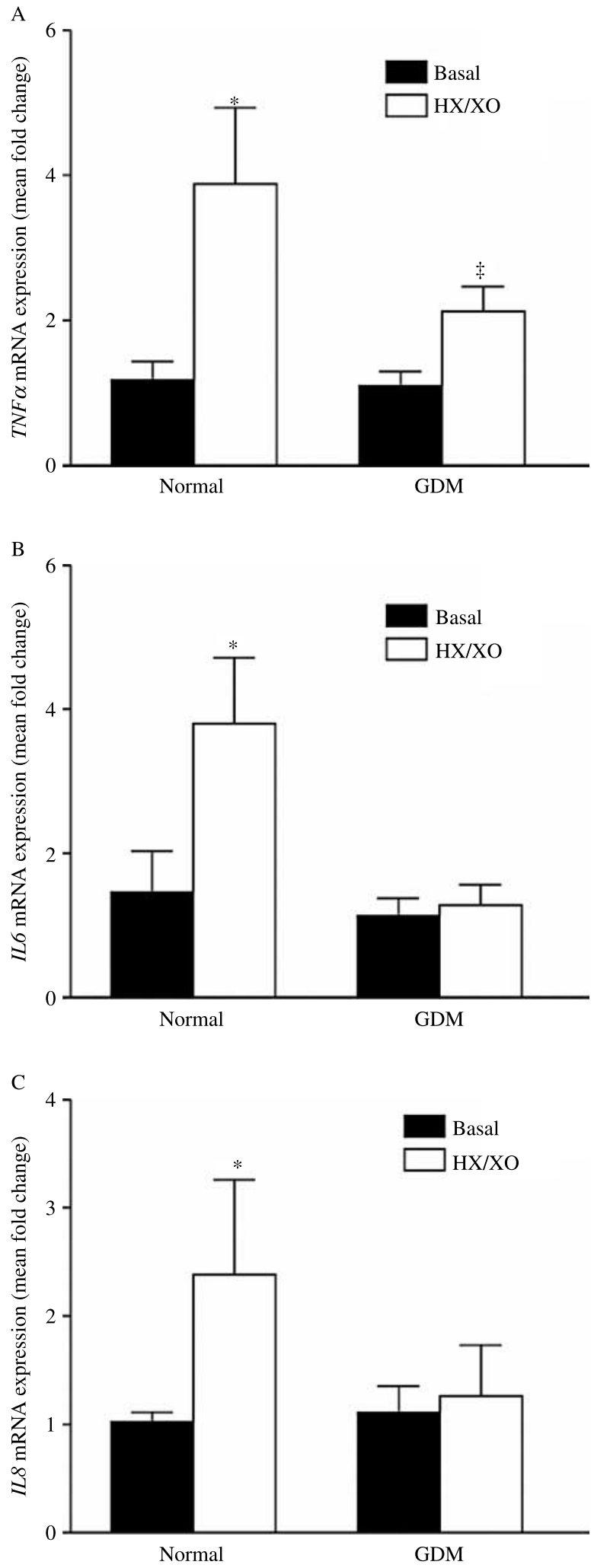

www.endocrinology-journals.org

\section{Participants}

Demographic data of all participants involved in the investigation is shown in Table 1 . There were no significant differences in maternal age, maternal BMI, foetal birth weight and gestational age between normal pregnant women and women with GDM. Fasting, 1- and 2-h plasma glucose concentrations at oral glucose tolerance test were significantly greater in women with GDM, compared with healthy pregnant women.

\section{Antioxidant gene expression in placenta and adipose tissue}

The mRNA expression of the antioxidant enzymes catalase $(C A T), G P X, G S R$ and SOD were determined in placental tissue obtained from both women with normal glucose tolerance $(n=23)$ and women with GDM $(n=17)$. The gene expression of CAT and GSR were significantly higher in the placenta obtained from women with GDM compared to normal pregnant women (Fig. 1A). There was no significant difference in the mRNA expression of GPX and SOD in placental tissue between healthy pregnant and GDM participants (Fig. 1A).

The mRNA expression of the antioxidant enzymes CAT, GPX, GSR and SOD were determined in omental (Fig. 1B) and subcutaneous (Fig. 1C) adipose tissue obtained from both women with normal glucose tolerance $(n=18)$ and women with GDM $(n=10)$. There was no significant difference in the mRNA expression of CAT, GPX, GSR and $S O D$ in both omental and subcutaneous adipose tissue between healthy pregnant and women with GDM.

\section{Effect of $\mathrm{HX} / \mathrm{XO}$ on placental cytokine and antioxidant expression}

To investigate the effects of oxidative stress on inflammatory cytokines and antioxidant gene expression, an ex situ tissue explant incubation model was used in which placental was incubated in the absence (control) and presence of $\mathrm{HX} / \mathrm{XO}$. Antioxidant and cytokine gene expression was analysed by qRT-PCR, and cytokine release was measured by ELISA.

Table 2 presents a summary of the effect of $\mathrm{HX} / \mathrm{XO}$ on cytokine release over $24 \mathrm{~h}$ from placenta from normal pregnant women and women with GDM. Only IL5 was

Figure 2 Effect of HX/XO on (A) TNF $\alpha$, (B) IL6, and (C) IL 8 mRNA expression from human placenta. Human term placental obtained from both normal pregnant women and women with GDM was stimulated with $0.5 \mathrm{mM} \mathrm{HX}+15 \mathrm{mU} / \mathrm{ml}$ XO for $24 \mathrm{~h}$. $18 \mathrm{~S} \mathrm{mRNA}$ expression was used for the normalisation of the data. Gene expression is displayed as mean fold change ratio as calculated by the $2^{-\Delta \Delta C_{t}}$ method. All data is displayed as the mean \pm s.E.M. ( $n=5$ per group). $* P<0 \cdot 05$ versus basal cytokine mRNA expression from normal placenta; ${ }^{\ddagger} P<0 \cdot 05$ versus basal cytokine mRNA expression from GDM placenta. 

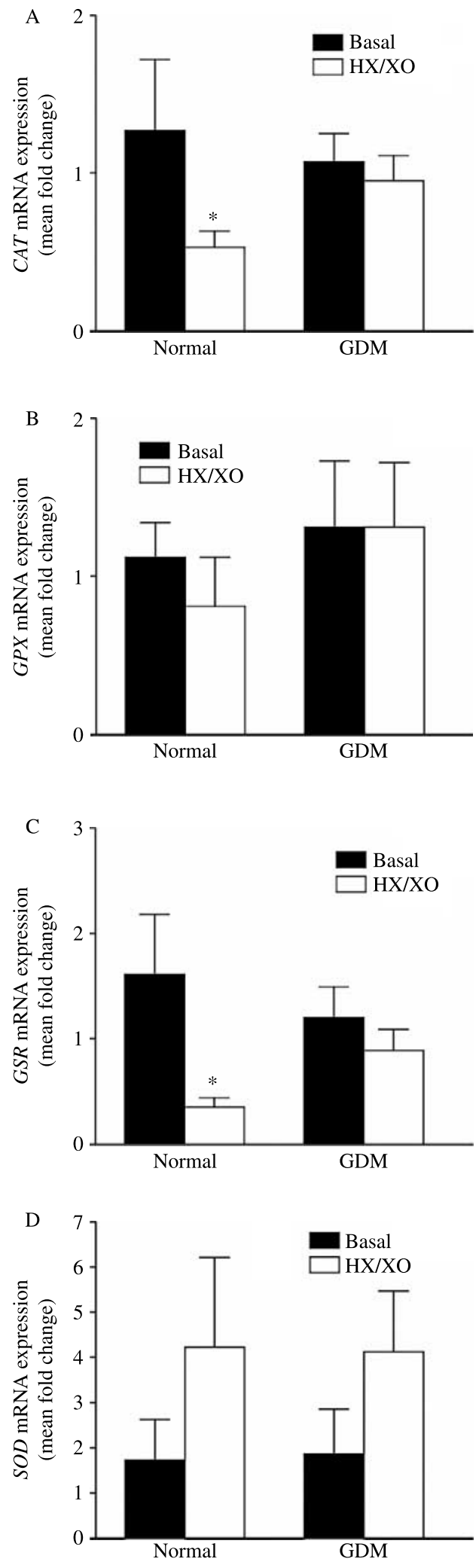

Journal of Endocrinology (2010) 204, 75-84 undetectable in all or most of the samples screened. This data was disregarded, as meaningful analysis of the data could not be made. Of all the other 16 cytokines assayed, there was no difference in the release between normal and GDM placenta under basal conditions. HX/XO significantly increased $(n=7)$ the release of 13 cytokines in normal placenta. These cytokines were IL1B, IL2, IL4, IL6, IL8, IL10, IL12(p70), IL17, G-CSF, GM-CSF, IFNG, MIP1 $\beta$, TNF $\alpha$. There was, however, no effect of $\mathrm{HX} / \mathrm{XO}$ treatment on the release of IL7, IL13 and MCP1 (MCAF) from normal placenta. On the other hand, in GDM placenta, HX/XO induced a significant increase in the release of only three cytokines: IL1B, MIP1 $\beta$ and TNF $\alpha(n=7)$. For IL1B, MIP1 $\beta$ and $\mathrm{TNF} \alpha$, tissues obtained from women with GDM, however, were at least $2 \cdot 5$-fold less responsive to an oxidative challenge than tissues from normal pregnant women.

Having shown that the cytokine secretion in response to an oxidative challenge from control and GDM placenta was different, the next aim was to determine the effect of $\mathrm{HX} / \mathrm{XO}$ treatment on gene expression. Figure $2 \mathrm{~A}-\mathrm{C}$ shows control and $\mathrm{HX} / \mathrm{XO}$-stimulated placental TNF $\alpha$, IL6, and IL8 mRNA expression ( $n=5$ per group). HX/XO significantly increased TNF $\alpha$, IL6 and IL 8 mRNA expression from normal placenta $(n=5)$. However, in GDM placenta, only $T N F \alpha$ mRNA significantly increased in response to $\mathrm{HX} / \mathrm{XO}$ treatment (Fig. 2A). GDM placental TNF $\alpha$ mRNA expression was threefold less responsive to an oxidative challenge than tissues from normal pregnant women. There was no effect of $\mathrm{HX} / \mathrm{XO}$ treatment on IL6 (Fig. 2B) and IL8 (Fig. 2C) gene expressions from normal GDM placenta.

The effect of $\mathrm{HX} / \mathrm{XO}$ treatment on antioxidant gene expression in normal and GDM placenta over $24 \mathrm{~h}$ is shown in Fig. 3A-D. In normal placenta, $\mathrm{HX} / \mathrm{XO}$ significantly decreased $(n=6)$ CAT (Fig. 3A) and GSR (Fig. 3C) gene expression in normal placenta, but not GDM placenta. There was no effect of $\mathrm{HX} / \mathrm{XO}$ on GPX gene expression in normal and GDM placenta (Fig. 3B). HX/XO increased $S O D$ mRNA expression in both normal and GDM placenta (Fig. 3D), however, this did not reach statistical significance.

Effect of $\mathrm{HX} / \mathrm{XO}$ on adipose tissue cytokine and antioxidant expression

To investigate the effects of oxidative stress on inflammatory cytokines and antioxidant gene expression, an ex situ tissue explant incubation model was used in which subcutaneous

Figure 3 Effect of $\mathrm{HX} / \mathrm{XO}$ on antioxidant enzyme mRNA expression from human placenta. Human term placental obtained from both normal pregnant women and women with GDM was stimulated with $0.5 \mathrm{mM} \mathrm{HX}+15 \mathrm{mU} / \mathrm{ml}$ XO for $24 \mathrm{~h}$. $18 \mathrm{~S}$ mRNA expression was used for the normalisation of the data. Gene expression is displayed as mean fold change ratio as calculated by the $2^{-\Delta \Delta C_{t}}$ method. All data is displayed as the mean \pm s.E.M. ( $n=6$ per group). ${ }^{*} P<0 \cdot 05$ versus basal antioxidant mRNA expression from normal placenta. 
and omental adipose tissues were incubated in the absence (control) and presence of $\mathrm{HX} / \mathrm{XO}$. Cytokine release was measured by ELISA and antioxidant gene expression was analysed by qRT-PCR.
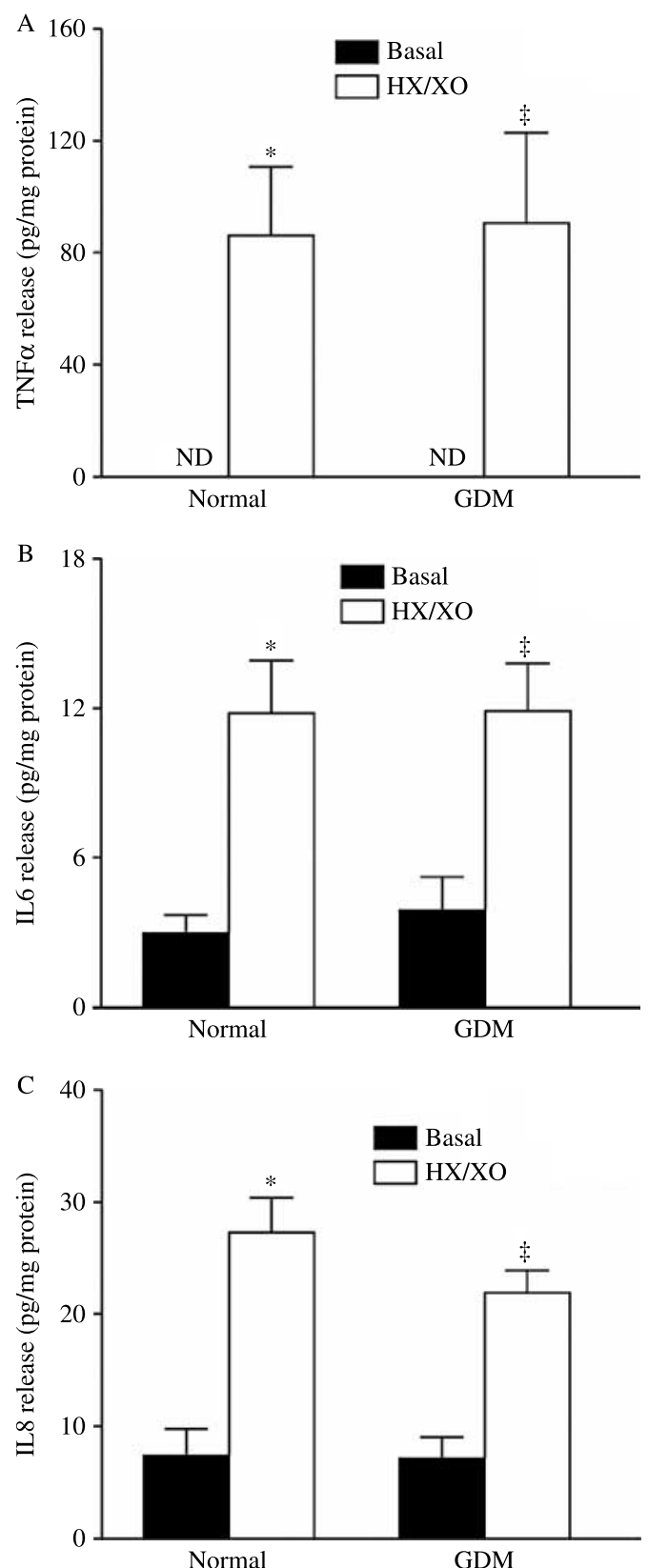

Figure 4 Effect of $\mathrm{HX} / \mathrm{XO}$ on (A) TNF $\alpha$, (B) IL6, and (C) IL8 release from human omental adipose tissue. Human term omental adipose tissue obtained from both normal pregnant women and women with GDM were stimulated with $0.5 \mathrm{mM} \mathrm{HX}+15 \mathrm{mU} / \mathrm{ml} \mathrm{XO}$ for $24 \mathrm{~h}$. All data is displayed as the mean \pm S.E.M. ( $n=6$ per group). $* P<0.05$ versus basal cytokine release from normal omental adipose tissue; ${ }^{\ddagger}$ versus $P<0 \cdot 05$ basal cytokine release from GDM omental adipose tissue. ND, not detected. Similar results were obtained for subcutaneous adipose tissue (data not shown).
Control and oxidant (HX/XO)-stimulated TNF $\alpha$, IL6, and IL8 release into the incubation medium for omental adipose tissue over $24 \mathrm{~h}$ is shown in Fig. 4A-C. Basal release of TNF $\alpha$ into the media was undetectable (Fig. 4A) and there was no difference in the release of IL6 (Fig. 4B) and IL8 (Fig. 4C) from normal or GDM omental adipose tissue under basal conditions. Adipose tissue explants that were exposed to an oxidative challenge $(\mathrm{HX} / \mathrm{XO})$ released significantly more TNF $\alpha$, IL6 and IL8 compared with basal release in both normal $(n=6)$ and GDM omental adipose tissue explants $(n=6)$. There was no difference in the magnitude of the cytokine response to $\mathrm{HX} / \mathrm{XO}$ between normal and GDM omental adipose tissue. Similar results were obtained for subcutaneous adipose tissue (data not shown).

In omental adipose tissue obtained from both normal and GDM women, $\mathrm{HX} / \mathrm{XO}$ treatment had no effect on $C A T$, GPX, GSR and $S O D$ gene expression ( $n=5$ per group). The effect of $\mathrm{HX} / \mathrm{XO}$ treatment on antioxidant gene expression omental adipose tissue (combined normal and GDM data) over $24 \mathrm{~h}$ is shown in Fig. 5. Similar results were obtained for subcutaneous adipose tissue (data not shown). The effect of $\mathrm{HX} / \mathrm{XO}$ treatment on 8 -isoprostane release was also investigated the data shown in Fig. 6. HX/XO treatment significantly increased 8 -isoprostane release from omental adipose tissue obtained from both normal and GDM women. There was no difference in the magnitude of response to HX/ $\mathrm{XO}$ between normal and GDM omental adipose tissue.

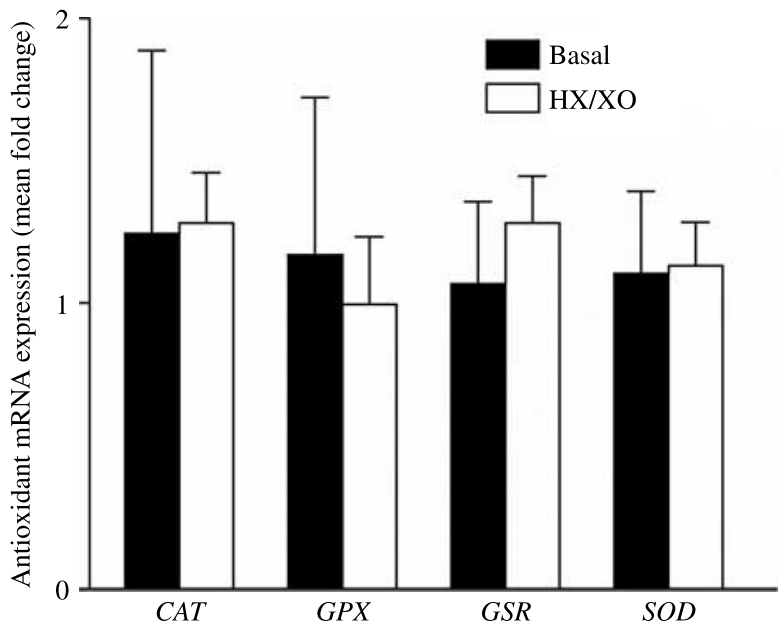

Figure 5 Effect of $\mathrm{HX} / \mathrm{XO}$ on antioxidant enzyme mRNA expression from human omental adipose tissue. Omental adipose tissue was stimulated with $0.5 \mathrm{mM} \mathrm{HX}+15 \mathrm{mU} / \mathrm{ml}$ XO for $24 \mathrm{~h}$. $18 \mathrm{~S}$ mRNA expression was used for the normalisation of the data. Gene expression is displayed as mean fold change ratio as calculated by the $2^{-\Delta \Delta C_{t}}$ method. As the antioxidant response between normal and GDM patients was the same, the data were combined data and displayed as the mean \pm S.E.M. $(n=5$ normal and $n=5$ GDM $)$. Similar results were obtained for subcutaneous adipose tissue (data not shown). 


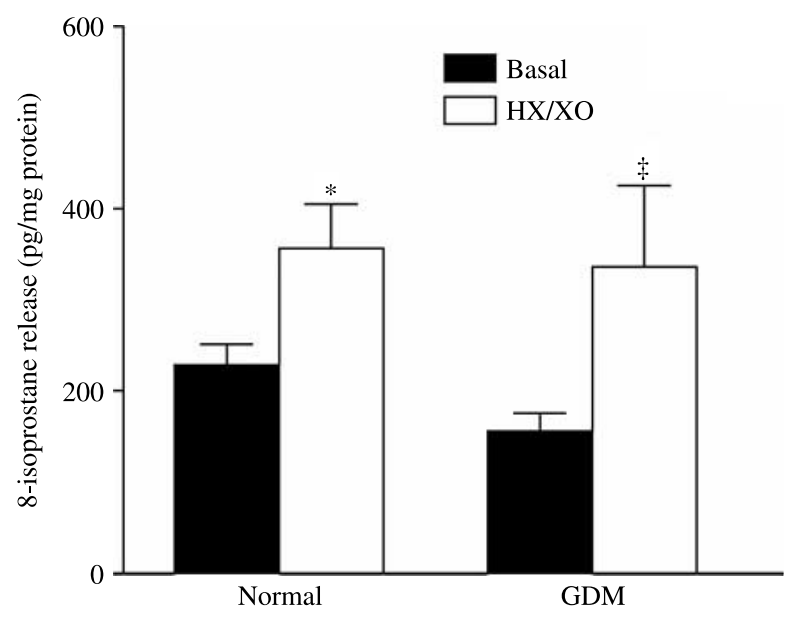

Figure 6 Effect of $\mathrm{HX} / \mathrm{XO}$ on 8-isoprostane release from human omental adipose tissue. Omental adipose tissue was stimulated with $0.5 \mathrm{mM} \mathrm{HX}+15 \mathrm{mU} / \mathrm{ml} \mathrm{XO}$ for $24 \mathrm{~h}$. All data is displayed as the mean \pm S.E.M. ( $n=3$ per group). ${ }^{*} P<0 \cdot 05$ versus basal 8 -isoprostane release from normal adipose tissue; ${ }^{\ddagger} P<0.05$ versus basal 8 -isoprostane release from GDM adipose tissue. Similar results were obtained for subcutaneous adipose tissue (data not shown).

\section{Discussion}

In this study, we have shown that the placenta obtained from women with GDM is characterised by increased antioxidant gene expression. In keeping with this, we have confirmed that GDM placenta is less responsive to an oxidative challenge than placental tissue from normal women. In normal placenta, $\mathrm{HX} / \mathrm{XO}$ induced a significant increase in cytokine release (IL1B, IL2, IL4, IL6, IL8, IL10, IL12(p70), IL17, G-CSF, GM-CSF, IFN $\gamma$, MIP1 $\beta$ and TNF $\alpha$ ) and mRNA expression (TNF $\alpha, I L 6$ and IL8). This was associated with a decrease in CAT and GPX gene expression. In contrast, in GDM placenta, $\mathrm{HX} / \mathrm{XO}$ induced a significant increase in the release of only three of the 16 cytokines assayed (IL1B, MIP1 $\beta$ and TNF $\alpha$ ). Additionally, in GDM placenta, there was no effect of $\mathrm{HX} / \mathrm{XO}$ on antioxidant gene expression. In contrast to the results obtained for placenta, there is no difference in antioxidant gene expression in omental and subcutaneous adipose tissue obtained from normal and GDM patients. Furthermore, both the subcutaneous and omental adipose tissue from women with and without GDM responded similarly to an oxidative challenge. Specifically, $\mathrm{HX} / \mathrm{XO}$ significantly stimulated proinflammatory cytokine release (TNF $\alpha$, IL6 and IL8) from both normal and GDM adipose tissues. Although there was no effect of $\mathrm{HX} / \mathrm{XO}$ on antioxidant gene expression, oxidative challenge did stimulate 8 -isoprostane release equally in normal and GDM omental and subcutaneous adipose tissue.

In this study, the response of normal and GDM placenta to $\mathrm{HX} / \mathrm{XO}$ was analysed in 16 cytokines. In response to oxidative stress, the release of 13 out of the 16 cytokines was significantly upregulated in placental extracts from normal pregnant women, whereas in GDM placental extracts, the release of only three of the cytokine was significantly increased. Furthermore, for these three cytokines, the magnitude of cytokine response was higher from normal placental extracts. The placental cytokine results obtained in this study are consistent with our previous studies demonstrating that when the placental tissue was subjected to $\mathrm{HX} / \mathrm{XO}$ system, TNF $\alpha$ release increased by 20 -fold from normal pregnant women and only fourfold from women with GDM (Coughlan et al. 2004b). In contrast to our previous findings (Coughlan et al. 2004b), in this study $\mathrm{HX} / \mathrm{XO}$ induced a significant increase in IL6 and IL8 release from normal placental extacts. It is of note that in this previous study, tissues were incubated under extremely hyperoxic conditions $\left(95 \% \mathrm{O}_{2}\right)$, whereas in the present study, placental tissue explants were performed in the presence of $8 \% \mathrm{O}_{2}$. Nevertheless, in GDM placental extracts, cytokine release was blunted in response to an oxidative challenge. The reduced cytokine response to oxidative stress by GDM placental extracts may be a consequence of decreased capacity to synthesise and thus release cytokines. In support of this, in this study, we have shown that $\mathrm{HX} / \mathrm{XO}$ significantly increased cytokine mRNA expression in normal placental extracts, but not in GDM placental extracts. In marked contrast, adipose tissue obtained from women with and without GDM both respond to $\mathrm{HX} / \mathrm{XO}$ by increasing $\mathrm{TNF} \alpha$, IL6 and IL8 cytokine release.

The cytokines that were induced by GDM represent early phase response genes that can then activate a number of intracellular signalling pathways including nuclear factor $\kappa \mathrm{B}$ (NFKB; Lappas et al. 2006). NFKB is a ubiquitous and inducible, transcription factor that is a central regulator of immune and inflammatory responses, cell adhesion, differentiation, redox metabolism and apoptosis (Courtois \& Gilmore 2006). We have previously shown that in human placenta, NFKB is activated in response to oxidative stress (Lappas et al. 2003, Coughlan et al. 2004b), proinflammatory cytokines (Lappas et al. 2006), and adipokines (Lappas et al. 2005), and this is associated with increased expression of proinflammatory mediators (Lappas et al. 2003, 2006, Coughlan et al. 2004b, Courtois \& Gilmore 2006, Lappas \& Rice 2007). This positive regulatory loop may amplify and perpetuate local inflammatory reactions. However, and in keeping with the data shown in this manuscript, we have also previously demonstrated that GDM is associated with decreased NFKB activity and that $\mathrm{HX} / \mathrm{XO}$ stimulated the activation of NFKB in placenta from healthy pregnant women but not women with GDM (Coughlan et al. 2004b).

Our previous studies demonstrate that when placental tissue was subjected to oxidative stress, 8-isoprostane release increased by twofold in normal pregnant women, but was unchanged in GDM (Coughlan et al. 2004b). Further to this, in this study we have shown that placental extracts from normal pregnant women, CAT and GSR mRNA expression were significantly decreased by $\mathrm{HX} / \mathrm{XO}$. There was, however, no effect of $\mathrm{HX} / \mathrm{XO}$ on antioxidant gene 
expression in GDM placental extracts. In contrast, although oxidative stress did not have any effect on antioxidant gene expression, there was increased 8-isoprostane release in adipose tissue obtained from both normal and GDM pregnant women. The observed changes in the antioxidant defence system are tissue specific, but it is evident that in both normal placenta, and normal GDM adipose tissue, induction of oxidative stress displaces the prooxidant-antioxidant balance of this defence system, by increasing the prooxidants while depleting the antioxidant capacities.

The ability of cells to accommodate oxidative stress may be enhanced by pre-exposure or pre-conditioning to a mild oxidative challenge, thus, inducing resistance to subsequent oxidative stress (Lu et al. 1993, Wiese et al. 1995, Lee \& Um 1999, Lappas \& Rice 2007). Changes in antioxidant concentrations in various tissues from experimental animal models of diabetes are reported, with the changes being related to the capacity of the tissues to adapt to oxidative stress. Some tissues, in response to diabetes, overexpress the genes for the antioxidant enzymes, whereas other tissues are more susceptible to oxidative damage (reviewed in Maritim et al. (2003)). It has also been proposed that in the early stages of diabetes there may be an initial elevation in antioxidant enzymes to counteract oxidative stress, whereas chronic diabetes continually depletes the sources of antioxidant enzymes. Thus, the blunted responses to oxidative stress by GDM placenta may be due to increased antioxidative capacity in these tissues. Although GDM is associated with increased in vivo oxidative stress, as evidenced by increased lipid peroxidation products in GDM placental tissue (Kinalski et al. 2001, Coughlan et al. 2004a, Lappas et al. 2004), studies on the tissue antioxidant enzyme activities in GDM placenta do not provide a consistent profile (Pustovrh et al. 2000, Kinalski et al. 2001, Coughlan et al. 2004a, Biri et al. 2006). However, in this study, we show that GDM placenta is associated with increased mRNA expression of CAT and GSR, the two antioxidant enzymes that decreased in response to $\mathrm{HX} / \mathrm{XO}$ in normal placenta. In adipose tissue from normal and GDM patients, however, there was no difference in antioxidant gene expression. Oxidative stress can cause vascular dysfunction in the placenta, leading to foetal compromise (Myatt et al. 2000). Thus, elevation of ROS in GDM placenta may induce pathophysiological effects that contribute to adverse pregnancy outcome. However, the elevated antioxidant gene expression in GDM placental may represent an adaptive mechanism protecting the foetus from ROS-induced damage.

In summary, in normal placenta, and normal GDM adipose tissue, but not GDM placenta, HX/XO exerts prooxidative and proinflammatory actions by increasing the release of proinflammatory mediators and ROS. Our data support the hypothesis that placenta from women with GDM display a reduced capacity to respond to oxidative stress. The blunted response to oxidative stress by GDM placenta may be a consequence of enhanced gene expression of antioxidant enzymes. Thus, GDM placental tissues have been pre-exposed and/or adapted to oxidative stress, and thus may be better prepared to accommodate an oxidative challenge.

\section{Declaration of interest}

There is no conflict of interest that could be perceived as prejudicing the impartiality of the research reported.

\section{Funding}

ML was a recipient of a National Health and Medical Research Council RD Wright Fellowship (grant no. 454777). The work described in this manuscript was funded by the National Health and Medical Research Council (grant no. 454310), Diabetes Australia Research Trust (DART), and the Medical Research Foundation for Women and Babies.

\section{Acknowledgements}

We would like to thank Ratana Lim from the Department of Obstetrics and Gynaecology for her technical assistance. The authors gratefully acknowledge the assistance of the Clinical Research Midwives Astrid Tiefholz, Gabrielle Fleming, Anne Beeston and Renee Grant; and the Obstetrics and Midwifery staff of the Mercy Hospital for Women for their co-operation.

\section{References}

Baynes JW 1991 Role of oxidative stress in development of complications in diabetes. Diabetes 40 405-412.

Beischer NA, Wein P, Sheedy MT \& Steffen B 1996 Identification and treatment of women with hyperglycaemia diagnosed during pregnancy can significantly reduce perinatal mortality rates. Australian and New Zealand Journal of Obstetrics and Gynaecology 36 239-247.

Biri A, Onan A, Devrim E, Babacan F, Kavutcu M \& Durak I 2006 Oxidant status in maternal and cord plasma and placental tissue in gestational diabetes. Placenta 27 327-332.

Chaudhari L, Tandon OP, Vaney N \& Agarwal N 2003 Lipid peroxidation and antioxidant enzyme in gestational diabetes. Indian Journal of Physiology and Pharmacology 47 441-446.

Coughlan MT, Vervaart PP, Permezel M, Georgiou HM \& Rice GE $2004 a$ Altered placental oxidative stress status in gestational diabetes mellitus. Placenta 25 78-84.

Coughlan MT, Permezel M, Georgiou HM \& Rice GE $2004 b$ Repression of oxidant-induced nuclear factor- $\kappa \mathrm{B}$ activity mediates placental cytokine responses in gestational diabetes. Journal of Clinical Endocrinology and Metabolism 89 3585-3594.

Courtois G \& Gilmore TD 2006 Mutations in the NF- $\kappa$ B signaling pathway: implications for human disease. Oncogene 25 6831-6843.

Desco MC, Asensi A, Marquez R, Martinez-Valls J, Vento M, Pallardo FV, Sastre J \& Vina J 2002 Xanthine oxidase is involved in free radical production in type 1 diabetes - protection by allopurinol. Diabetes 51 1118-1124.

Evans HE, Rosenfeld W, Jhaveri R, Conception L \& Zabaleta I 1986 Oxidant mediated lung disease in newborn infants. Journal of Free Radicals in Biology and Medicine 2 369-372.

Kautzky-Willer A, Prager R, Waldhausl W, Pacini G, Thomeseth K, Wagner OF, Ulm M, Streli C \& Ludvik B 1997 Pronounced insulin resistance and inadequate $\beta$ cell secretion characterize lean gestational diabetes during and after pregnancy. Diabetes Care 20 1717-1723. 
Kinalski M, Sledziewski A, Telejko B, Kowalska I, Kretowski A, Zarzycki W \& Kinalska I 2001 Lipid peroxidation, antioxidant defence and acid-base status in cord blood at birth: the influence of diabetes. Hormone and Metabolic Research 33 227-231.

Lappas M \& Rice GE 2007 The role and regulation of the nuclear factor kappa B signalling pathway in human labour. Placenta 28 543-556.

Lappas M, Permezel M \& Rice GE 2003 N-acetyl-cysteine inhibits phospholipid metabolism, pro-inflammatory cytokine release, protease activity, and nuclear factor- $\kappa \mathrm{B}$ deoxyribonucleic acid-binding activity in human fetal membranes in vitro. Journal of Clinical Endocrinology and Metabolism 88 1723-1729.

Lappas M, Permezel M \& Rice GE 2004 Release of pro-inflammatory cytokines and 8-isoprostane from placenta, adipose tissue and skeletal muscle from normal pregnant women and women with gestational diabetes mellitus. Journal of Clinical Endocrinology and Metabolism 89 5627-5633.

Lappas M, Permezel M \& Rice GE 2005 Leptin and adiponectin stimulate the release of pro-inflammatory cytokines and prostaglandins from human placenta and maternal adipose tissue via NF- $\kappa B$, PPAR $-\gamma$ and ERK 1/2. Endocrinology 146 3334-3342.

Lappas M, Yee K, Permezel M \& Rice GE 2006 Lipopolysaccharide and TNF- $\alpha$ activate the nuclear factor kappa B pathway in the human placental JEG-3 cells. Placenta 27 568-575.

Lee BR \& Um HD 1999 Hydrogen peroxide suppresses U937 cell death by two different mechanisms depending on its concentration. Experimental Cell Research 248 430-438.

Lee AJ, Hiscock RJ, Wein P, Walker SP \& Permezel M 2007 GDM: clinical predictors and long-term risk of developing type 2 diabetes. Diabetes Care 30 878-883.

Livak KJ \& Schmittgen TD 2001 Analysis of relative gene expression data using real-time quantitative PCR and the $2^{-\Delta \Delta C_{\mathrm{t}}}$ method. Methods 25 402-408.

Lu D, Maulik N, Moraru II, Kreutzer DL \& Das DK 1993 Molecular adaptation of vascular endothelial cells to oxidative stress. American Journal of Physiology 264 C715-C722.

Madazl R, Tuten A, Calay Z, Uzun H, Uludag S \& Ocak V 2008 The incidence of placental abnormalities, maternal and cord plasma malondialdehyde and vascular endothelial growth factor levels in women with gestational diabetes mellitus and nondiabetic controls. Gynecologic and Obstetric Investigation 65 227-232.

Maritim AC, Sanders RA \& Watkins JB 2003 Diabetes, oxidative stress, and antioxidants: a review. Journal of Biochemical and Molecular Toxicology 17 24-38.

Myatt L, Kossenjans W, Sahay R, Eis A \& Brockman D 2000 Oxidative stress causes vascular dysfunction in the placenta. Journal of Maternal Fetal and Neonatal Medicine 9 79-82.

Peuchant E, Brun J-L, Rigalleau V, Dubourg L, Thomas M-J, Daniel J-Y, Leng J-J \& Gin H 2004 Oxidative and antioxidative status in pregnant women with either gestational or type 1 diabetes. Clinical Biochemistry 37 293-298.

Pustovrh C, Jawerbaum A, Sinner D, Pesaresi M, Baier M, Micone P, Gimeno M \& Gonzalez ET 2000 Membrane-type matrix metalloproteinase-9 activity in placental tissue from patients with pre-existing and gestational diabetes mellitus. Reproduction, Fertility, and Development 12 269-275.

Reti NG, Lappas M, Huppertz B, Riley C, Wlodek ME, Henschke P, Permezel M \& Rice GE 2007 Effect of high oxygen on placental function in short-term explant cultures. Cell and Tissue Research 328 607-616.

Singh U, Devaraj S \& Jialal I 2005 Vitamin E, oxidative stress, and inflammation. Annual Review of Nutrition 25 151-174.

Trocino RA, Akazawa S, Ishibashi M, Matsumoto K, Matsuo H, Yamamoto H, Goto S, Urata Y, Kondo T \& Nagataki S 1995 Significance of glutathione depletion and oxidative stress in early embryogenesis in glucose-induced rat embryo culture. Diabetes 44 992-998.

West IC 2000 Radicals and oxidative stress in diabetes. Diabetic Medicine 17 171-180.

Wiese AG, Pacifici RE \& Davies KJA 1995 Transient adaptation to oxidative stress in mammalian cells. Archives of Biochemistry and Biophysics 318 231-240.

\section{Received in final form 20 September 2009 \\ Accepted 15 October 2009 \\ Made available online as an Accepted Preprint 15 October 2009}

